\title{
ALIARSE (REGIONALMENTE) CONTRA LA COVID-19: SICA Y CARICOM
}

\author{
UNITING (REGIONALLY) AGAINST COVID-19: \\ SICA AND CARICOM
}

\section{FAIRE BLOC (RÉGIONAL) CONTRE LA COVID-19: SICA ET CARICOM}

\author{
Kevin Parthenay \\ Université de Tours, Francia \\ kevin.parthenay@univ-tours.fr
}

\begin{abstract}
RESUMEN: La crisis sanitaria mundial relacionada con la Covid-19 (sARs-Cov-2) ha generado tensión en el conjunto de los sistemas políticos del planeta, desestabilizó los sistemas económicos y sociales y supuso un desafío para las organizaciones internacionales y regionales. A pesar de que en América Central los Estados miembros del Sistema de Integración Centroamericano (Sica) y, en el Caribe, los Estados miembros de la Caricom se caracterizan por su fragilidad, las dos regiones presentan un desempeño sorprendente en lo relativo a la gestión de la crisis sanitaria. Ponemos a prueba hipótesis relativas al aprendizaje institucional, a la ayuda exterior y a la distribución espacial, para explicar esta contradicción aparente de la resistencia ante la crisis sanitaria, a pesar de la debilidad de las estructuras regionales del Estado.

Palabras clave: Sica; Caricom; regionalismo; crisis sanitaria; resiliencia; Covid-19.
\end{abstract}

\section{Traducción de Rafael Segovia, GC Idiomas}

Aвstract: The global health crisis linked to Covid-19 (SARS-Cov-2) has put all political systems around the world under strain, challenged economic and social systems and put international and regional organizations to the test. Although in Central America and the Caribbean, the member states of the Central American Integration System (Sica) and of Caricom respectively are characterized by fragility and vulnerability, the two regions report an astonishing performance in the management of the health crisis. 
Testing hypotheses relating to institutional learning, foreign aid and spatial distribution, we explain this apparent contradiction within the resilience in the face of the health crisis despite the weakness of regional state structures.

Keywords: Sica; Caricom; regionalism; health crisis; resilience;

Covid-19.

\section{Traducción de Fionn Petch, GC Idiomas}

Résumé: La crise sanitaire globale liée à la Covid-19 (sARs-Cov-2) a mis en tension l'ensemble des systèmes politiques de la planète, éprouvé les systèmes économiques et sociaux et mis à l'épreuve les organisations internationales et régionales. Alors qu'en Amérique centrale, les Etats membres du Système d'Intégration Centraméricain (Sica), et dans la Caraïbe, les Etats membres de la Caricom, sont caractérisées par leur fragilité et leur vulnérabilité, les deux régions font état d'une étonnante performance en matière de gestion de la crise sanitaire. Testant des hypothèses relatives à l'apprentissage institutionnel, l'aide extérieure et la distribution spatiale, nous expliquons cette apparente contradiction de la résistance face à la crise sanitaire en dépit de la faiblesse des structures étatiques régionales.

Mots-clefs: Sica ; Caricom ; régionalisme ; crise sanitaire ; résilience ; Covid-19.

Fecha de recepción: octubre de 2020

Fecha de aceptación: febrero de 2021 


\section{INTRODUCCIÓN}

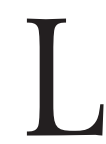

a crisis sanitaria global vinculada a la Covid-19 (SARS-Cov-2) ha sacado a flote tensiones en todos los sistemas polítiCiales. ${ }^{1}$ Los Estados más débiles o vulnerables han tenido ciales. ${ }^{1}$ Los Estados más débiles o vulnerables han tenido que hacer frente a situaciones de emergencia para proteger a su población, a pesar de la escasez de recursos económicos, materiales y humanos. Pero no sólo se puso a prueba a los Estados, sino también a las organizaciones internacionales y regionales (OR). Tras haber extendido, durante dos décadas, sus roles y su lugar en los sistemas de gobernanza multinivel, ${ }^{2}$ intervinieron lógicamente en esta crisis sanitaria global. Sin embargo, el alcance de su intervención y su desempeño siguen sin explorarse.

Así pues, hay un doble interés en observar las respuestas del Sistema de la Integración Centroamericana (Sica) y de la Comunidad del Caribe (Caricom) ante la Covid-19. En primer lugar, se considera que los Estados de ambas regiones, América Central y el Caribe, son débiles y vulnerables, y que estas dos or han tenido la oportunidad de desempeñar un papel central. En segundo lugar, ambas regiones han visto crecer, en las últimas décadas, la importancia de sus respectivas organizaciones regionales. A raíz de estas dos constataciones iniciales, se observa un aparente buen resultado de las acciones y estrategias llevadas a cabo por el Sica, la Caricom y los Estados miembros respectivos, debido al impacto limitado de la primera oleada de contagios. En efecto, estas oR contrastan con intervenciones limitadas o inexistentes para otros bloques regionales del continente, en particular

${ }^{1}$ Queremos expresar nuestro sincero agradecimiento a las/los dos evaluadores anónimos por sus valiosos comentarios y a los coordinadores de este número especial, Thomas Legler y Élodie Brun.

${ }^{2}$ Liesbet Hooghe, Gari Marks, "Types of Multi-Level Governance". European Integration online Papers (EIoP), vol. 5, núm. 11, 12 de octubre de 2001, http://dx.doi.org/10.2139/ssrn.302786 
la Comunidad Andina de Naciones (CAN), el Mercado Común del Sur (Mercosur) o la Comunidad de Estados Latinoamericanos y del Caribe (Celac) ${ }^{3}$

En este artículo intentaremos realizar un primer análisis de las situaciones regionales centroamericana y caribeña. Al principio revisamos las peculiaridades de los dos espacios regionales. Después de hacer un recuento de las hipótesis que permiten explicar el impacto diferenciado de la Covid-19 en América Central y el Caribe en comparación con otras regiones del mundo, proponemos una perspectiva empírica del impacto de la circulación del virus durante la primera ola, antes de establecer un panorama de la gestión de crisis en ambas regiones, abordando en particular la cuestión de los dispositivos institucionales y las ayudas exteriores. Aprovechamos esta reflexión para establecer varias observaciones conclusivas sobre el estado de los regionalismos caribeño y centroamericano.

\section{CARICOM/Sica: Estados, ORGANIZAGIONES E Historias REGIONALES}

Centroamérica (Sica) y el Caribe (Caricom) comparten un estatuto que los torna singulares y los une: la vulnerabilidad. En América Central, esta vulnerabilidad se expresa en términos de desarrollo socioeconómico (con excepción de Costa Rica y Panamá). La debilidad de las estructuras estatales, que tiene sus raíces en una estructura de acumulación capitalista desigual heredada de la colonización y en dinámicas políticas estructurales del periodo contemporáneo (neopatrimonial, corrupción, cooptación y captura de los aparatos estatales), explica los muy bajos niveles de gasto público en salud y la fragilidad de la capacidad de reacción ante un escenario pandémico (infraestructura de acogida, materiales/productos

${ }^{3}$ Ver la contribución de Thomas Legler sobre estos casos en este número especial. 
médicos y farmacéuticos). Por ello, las intervenciones exteriores -mediante apoyo técnico y/o ayudas financieras- constituyen un elemento esencial para el funcionamiento de las políticas de salud en general y para la gestión de la crisis sanitaria vinculada a la Covid-19. ${ }^{4}$

En una tónica similar, todos los Estados miembros de la Caricom pertenecen a la categoría de los pequeños Estados insulares en desarrollo (PIED), aunque Belice, Guyana y Surinam no comparten la característica de la insularidad. A diferencia de América Central, los Estados caribeños están clasificados más bien como Estados de "ingresos medios" (o incluso altos), pero el reconocimiento global de la categoría PIED ha permitido destacar otros tipos de vulnerabilidades: una económica, debida a la dependencia casi absoluta del turismo, y otra ambiental, debida al cambio climático. Al igual que la región centroamericana, los Estados caribeños tienen una limitada disponibilidad de recursos para responder a la complejidad de su situación nacional, incluyendo las emergencias sanitarias. ${ }^{5}$

Si bien ambas regiones comparten esta vulnerabilidad ante los choques externos, siguen siendo singulares en cuanto a los riesgos de la crisis sanitaria. Centroamérica, como espacio de circulación de bienes e individuos, ha enfrentado prioritariamente un imperativo de control de flujos (procedentes del exterior en primer lugar, del seno de la región en segundo). Para el Caribe, la dimensión insular facilitó la contención de la circulación del virus mediante el control de los puntos de entrada, limitados numéricamente por su naturaleza. En ese sentido, dado que los Estados caribeños viven principalmente del turismo internacional, las repercusiones

${ }^{4}$ Giovanni Agostinis y Kevin Parthenay, "Exploring the Determinants of Regional Health Governance modes in the global South: A Comparative analysis of Central and South America", Review of International Studies (en proceso de revisión).

5 Madhuvanti M. Murphy et al., "Covid-19 Containment in the Caribbean: The Experience of Small Island Developing States”, Research in Globalization, núm. 2, 2020, pp. 1-9. 
económicas de la pandemia (especialmente en Europa y América del Norte) han sido uno de los principales focos de preocupación.

En ambos casos, sin embargo, la escasez de recursos ha originado una estrategia común, la de previsión y prevención, incluso antes de los escenarios de reacción. El Caribe, como veremos más adelante, en un primer momento invirtió en gran medida en el control de los flujos procedentes del exterior para impedir la entrada del virus a las islas.

\section{Cuadro 1}

Estados miembros del Sica y de la Caricom

\begin{tabular}{ll}
\hline \multicolumn{1}{c}{ Sica } & \multicolumn{1}{c}{ Caricom } \\
\hline República Dominicana & Antigua y Barbuda \\
Costa Rica & Bahamas \\
Panamá & Barbados \\
Honduras & Belice \\
Guatemala & Dominica \\
Nicaragua & Granada \\
El Salvador & Guyana \\
Belice & Haití \\
& Jamaica \\
& Monserrat \\
& Santa Lucía \\
& San Cristóbal y Nieves \\
& San Vicente y las Granadinas \\
& Surinam \\
& Trinidad y Tobago \\
\hline
\end{tabular}

Fuentes: Sica, https:/ /www.sica.int (consulta del 26 de enero de 2021) y Caricom, https://caricom.org (consulta del 26 de enero de 2021).

Esta configuración de la vulnerabilidad, en lo que se refiere a los Estados miembros, ha permitido a las organizaciones regionales desempeñar un papel especial. No obstante, hay que señalar que este papel y las expectativas asociadas no son una novedad para ambas regiones. Producto de historias 
singulares, comparten hasta la fecha dos realidades comunes: la de tomar sus decisiones sobre una base de unanimidad entre sus miembros y la de intervenir en las situaciones de crisis para ayudar a superar las debilidades de los Estados miembros, aunque mediante estrategias diversas.

La primera organización regional, la Caricom, surge de lo que se conoce como la primera "ola voluntarista" (décadas de 1950 a 1970) de regionalismo latinoamericano y la segunda, el Sica, de una ola posterior (década de 1990), llamada "regionalismo abierto" (ola neoliberal). ${ }^{6}$

La Caricom, creada en 1973, es el producto institucional de mecanismos de cooperación económica y comercial anteriores (como el Carifta de 1968). Con 15 Estados miembros (y cinco miembros asociados: Anguila, Bermudas, Islas Vírgenes Británicas, Islas Caimán, Islas Turcas y Caicos), la Caricom se estableció para promover la integración económica, la cooperación funcional y la coordinación de la política exterior de conformidad con el Tratado de Chaguaramas de $1973 .{ }^{7} \mathrm{Si}$ bien desde su creación el sistema regional ha tropezado con dificultades para armonizar las políticas exteriores, la Caricom ha logrado sin embargo desempeñar un papel central en la coordinación de sus Estados miembros con respecto al exterior, en particular en el seno de las instituciones financieras internacionales, las or y las Cumbres de las Américas. ${ }^{8}$ Por otra parte, la agenda de su principal órgano, las Cumbres de Jefes de Gobierno, se ha centrado regularmente en las situaciones de crisis, como ocurrió durante la crisis económica de 2009, el terremoto haitiano de 2010 y los daños causados por

${ }^{6}$ Olivier Dabène, Politics of Regional Integration in Latin America, Nueva York, Palgrave Macmillan, 2009.

7 José Briceño-Ruiz y Andrés Puntigliano Rilarola (eds.), Resilience of Regionalism in Latin America and the Caribbean: Development and Autonomy, Basingstoke, Palgrave Macmillan, 2013; Jessica Byron, "Summitry in the Caribbean Community: A Fundamental Feature of Regional Governance”, en Macace Gordon et al. (eds.), Summits and Regional Governance. The Americas in Comparative Perspective, Nueva York, Routledge, 2016, pp. 114-131.

8 Jessica Byron, art. cit. 
los huracanes en Haití, Granada, Jamaica, las Islas Caimán en los últimos años.

El Sica, por su parte, surgió de la ola de reactivación de los regionalismos a principios de la década de 1990, tras los conflictos civiles armados que afectaron la región, asumiendo la continuación de la Organización de los Estados Centroamericanos (Odeca), creada en 1951. De acuerdo con la doctrina del "regionalismo abierto", 9 el Sica se inscribe en una secuencia de democratización y pacificación de la región, promoviendo al mismo tiempo el desarrollo económico y comercial. Inmediatamente después de su creación, el Sica entró en una fase de inercia de la que sólo pudo salir "gracias" a la gestión de un desastre natural, vinculado con el paso del huracán Mitch en octubre de 1998, que relegitimó su existencia. El apoyo de la Unión Europea (UE) para su desarrollo institucional a partir de 2004 contribuyó a su burocratización, pero no aumentó significativamente la legitimidad de su existencia regional. La organización regional fue objeto de constantes críticas por su ineficacia en la crisis hondureña (2009), la de los migrantes cubanos (2015) y la nicaragüense (2018), sufrió la polarización de las posiciones continentales con respecto a la crisis venezolana y se mantenía en una situación de extrema vulnerabilidad financiera al seguir dependiendo esencialmente de contribuciones externas. ${ }^{10}$

La historia de estas dos or está íntimamente relacionada con las crisis y los desastres naturales. Si bien las han afectado, constituyen no obstante una fuerza de impulso significativa, en particular vinculada al fenómeno de canalización de recursos exteriores, claves para su funcionamiento, en las situaciones críticas o de emergencia. En el caso de la Caricom, aproximadamente $52 \%$ del presupuesto proviene de finan-

${ }^{9}$ Comisión Económica para América Latina, Cepal, El regionalismo abierto en América Latina y el Caribe: La integración económica al servicio de la transformación productiva con equidad, Santiago, 1994.

${ }^{10}$ Kevin Parthenay, "L'intégration régionale en Amérique centrale. Une sociologie politique du changement (1991-2012)", tesis doctoral en Ciencias Políticas, París, Sciences Po, 2013. 
ciación externa. ${ }^{11}$ En el de Sica, alrededor de $70 \%$ del presupuesto de la organización procede también de donantes extranjeros. ${ }^{12}$ Algunos sectores, incluido el de la salud, a través del Consejo de Ministros de Salud de Centroamérica y República Dominicana (Cimsica), reciben 90\% de sus recursos de financiación externa (Taiwán, Fondo España-Sica, Centers for Disease Control and Prevention o Centros para el Control y la Prevención de Enfermedades). ${ }^{13}$

Teniendo en cuenta esta situación, el ejercicio de una "gobernanza eficaz" en este escenario de crisis sanitaria plantea dudas, sobre todo cuando los donantes tradicionales han visto reducidas sus propias capacidades de intervención al verse afectados por la pandemia (véase la sección 3). Sin embargo, estas or han mostrado cierta capacidad de reacción, que se puede analizar mediante varias hipótesis.

\section{UNA GOBERNANZA REGIONAL EFECTIVA: SUPUESTOS}

Habida cuenta de las estructuras sociohistóricas y de la posición geopolítica de los dos conjuntos regionales, pueden presentarse varias hipótesis explicativas de una gobernanza regional eficaz: espacial, político-institucional y de externalidad.

Hipótesis espacial. Una primera hipótesis se refiere a la localización y a las características geográficas de las dos regiones consideradas. En el caso centroamericano, este istmo que une al continente americano siempre ha sido un espacio de intensa circulación, de movilidad de bienes y de personas, propicio a una rápida propagación del virus. Esta caracterís-

${ }^{11}$ Comunidad del Caribe, Caricom, "Brief on Caricom Relations with International Development Partners", 2016, https://caricom.org/ Brief\% 20on \% 20Caricom \% 20\% 20Relations \% 20with\%20IDPs.pdf (consulta del 2 de octubre de 2020).

12 Kevin Parthenay, op. cit.

13 SE-Comisca, Informe de Gestión Financiera 2015-2016, San Salvador, 2016. 
tica la convierte en una región de alto riesgo. En el mismo registro geográfico, el espacio caribeño podría considerarse menos peligroso debido a su dimensión predominantemente insular (con excepción de Belice, Guyana y Surinam). Sólo la dependencia económica del exterior, en particular del turismo, constituye un efecto indirecto potencialmente negativo de sus características geográficas, si bien las medidas de confinamiento adoptadas en Europa y América del Norte han contenido preventivamente este riesgo. Una vez disminuido ese riesgo, el espacio caribeño tenía en realidad barreras "naturales" para limitar la movilidad del virus en la escala regional. Sin embargo, mantener el intercambio comercial y establecer una "travel bubble" (burbuja de viajes) para los Estados de la Caricom, que se extendió a los Estados de la Organización de los Estados del Caribe Oriental (oEcs), desmiente esta hipótesis desde el momento en que el virus apareció en el espacio caribeño. ${ }^{14}$ Por lo tanto, si se excluye la hipótesis espacial para el Sica, ésta sigue siendo poco explicativa para la Caricom.

Hipótesis política. Otra hipótesis se centra en las medidas que tomaron los gobiernos y las or de las dos regiones para luchar contra la propagación de la Covid-19. Se compone de dos dimensiones: la primera corresponde a la aplicación de una estrategia de prevención, a sabiendas de que los aparatos estatales no podrían hacer frente en caso de propagación del virus (realismo estratégico); la segunda se refiere a la experiencia adquirida en el aprendizaje de los Estados de las dos regiones en lo relativo a la gestión de crisis sanitarias -dengue, zika, entre otros-y de desastres naturales -huracán, sequía, inundaciones- (institucionalismo histórico). En lo que respecta al segundo aspecto, el reto consiste en identificar la existencia de conocimientos especializados

14 Jascene Dunkley-Malc, "Antiguan Government Establishes 'Travel Bubble' for Caribbean Travelers", Caricom Today, 10 de julio de 2020, https://today.caricom.org/2020/07/10/antiguan-government-establishes-travel-bubble-for-caribbean-travelers/ (consulta del 2 de octubre de 2020). 
construidos y acumulados como consecuencia de la frecuencia de las situaciones de emergencia que experimentan ambas regiones, una pericia puesta en práctica ante la pandemia. En este caso, esta hipótesis del patrimonio institucional daría aún más protagonismo a las or, a veces denominadas "burocracia regional", ${ }^{15}$ en la medida en que la pandemia coincide con un contexto político desfavorable a la cooperación y a la convergencia política entre los Estados miembros de la región.

Hipótesis de la externalización. La última hipótesis que formulamos se sitúa en la prolongación de una tradición analítica relativa a los dos subconjuntos regionales: la influencia de actores exteriores. En este sentido, esta hipótesis consiste en atribuir la resistencia frente a la Covid-19 al apoyo de actores extrarregionales, que pueden ser tanto organizaciones internacionales como cooperantes estatales extranjeros o no estatales, y se justifica por el legado de una dependencia de la financiación exterior, como ya se ha mencionado, con respecto a los presupuestos de las organizaciones regionales. ${ }^{16}$ También se justifica por la tensión geopolítica en la región entre Estados Unidos, China y Rusia, que ha hecho de la crisis sanitaria una oportunidad para ampliar la presencia china y rusa en el continente. ${ }^{17}$ Esta realidad también remite a las rivalidades entre agentes intermedios, en particular Taiwán en América Central, frente a la República Popular China (RPC).

${ }^{15}$ Kevin Parthenay, "Autonomy in Latin American Regional Bureaucracies: The Role and Place of the General Secretaries", Critique Internationale, vol. 87, núm. 2, 2020, pp. 153-174.

${ }^{16}$ Kevin Parthenay, loc. cit.; Anne Marie Hoffman, "The Finance of the Caribbean Community (Caricom )", en Frank Mattheis y Ulf Engel (eds.), The Finances of Regional Organisations in the Global South: Follow the Money, Abingdon, Routledge, 2020.

${ }^{17}$ Diego Telias y Francisco Urdíñez, "China's Foreign Aid Determinants: Lessons from a Novel Dataset of the Mask Diplomacy during the COVID-19 Pandemic", documento inédito, doi: 10.13140/RG. 2.2.27199.5 3929 
Por lo tanto, nos centraremos específicamente en la dimensión político-institucional y en la relación con los actores externos en esta crisis sanitaria, así como en la interrelación de estas dos realidades, para interpretar el impacto menor de la Covid-19 en la primera ola.

\section{HAGer Frente A La PROPAGAGión del Virus}

En comparación con otras partes del mundo, América Central y el Caribe parecen haber resistido mejor la primera ola de la Covid-19. Aunque América en su conjunto se ha visto afectada con retraso respecto a Europa ("outbreak" o brote, marzo-abril), se observa una rápida intensificación a partir de mediados de abril y, esencialmente, durante mayo de 2020. Sin embargo, a pesar de este crecimiento continental, América Central y el Caribe han quedado relativamente "indemnes". Como indican las cifras (véase el cuadro 2), tanto el número de casos de contaminación como el número de muertes son inferiores en las dos regiones consideradas, en comparación con otras partes del continente americano y de Europa. A pesar de que la densidad de población es menor, el índice de letalidad (case fatality rate) sigue siendo inferior en ambas regiones.

En cuanto a la difusión de la pandemia, la República Dominicana fue el primer Estado perteneciente al Sica afectado por el virus, el 1 de marzo, seguido de Costa Rica, el 6 de marzo. En cambio, el último Estado perjudicado fue Belice, también miembro de la Caricom, el 23 de marzo. A este respecto, se observa que los Estados del Caribe han sido golpeados en forma más tardía por el virus. Jamaica fue el Estado de la Caricom que identificó su primer caso, el 11 de marzo. El último fue San Cristóbal y Nieves, casi dos semanas después, el 25 de marzo. El ritmo de propagación del virus en ambas regiones también ha sido más lento, lo que explica el menor número de 
casos de infección y muerte y menores tasas de mortalidad por el virus. ${ }^{18}$

\section{Cuadro 2}

Efectos diferenciados de la pandemia

\begin{tabular}{lcccccc}
\hline & $\begin{array}{c}\text { Casos de } \\
\text { contaminación }\end{array}$ & $\begin{array}{c}\text { Población } \\
\text { (en millones, } \\
\text { 2019) }\end{array}$ & $\begin{array}{c}\text { Porcentaje de } \\
\text { la población } \\
\text { total }\end{array}$ & Decesos & $\begin{array}{c}\text { Porcentaje de } \\
\text { la población } \\
\text { total }\end{array}$ & $\begin{array}{c}\text { Índice de } \\
\text { letalidad }\end{array}$ \\
\hline Europa & 3995425 & 513.5 & 0.78 & 216864 & 0.042 & $5.88 \%$ \\
América Central & $\mathbf{2 7 2 8 0 0}$ & 49.9 & $\mathbf{0 . 5 6}$ & $\mathbf{7 3 0 0}$ & $\mathbf{0 . 0 1 4}$ & $\mathbf{0 . 0 6 \%}$ \\
Caribe & $\mathbf{1 5 7 5 0 0}$ & 43.13 & $\mathbf{0 . 3 6}$ & $\mathbf{2 6 0 0}$ & $\mathbf{0 . 0 0 6}$ & $\mathbf{0 . 0 2 \%}$ \\
América del Norte & 6300000 & 497.5 & 1.27 & 245400 & 0.049 & $1.96 \%$ \\
América del Sur & 5800000 & 429.3 & 1.35 & 189100 & 0.044 & $1.51 \%$ \\
\hline
\end{tabular}

Fuente: OMs/ops (datos al 25 de agosto de 2020).

Los datos de contaminación, decesos y letalidad se tomaron a finales de agosto de 2020 y son ilustrativos de los efectos de la Covid-19 en el marco de la primera ola pandémica.

Desde la aparición del primer caso, las modalidades de contagio han variado entre las dos regiones. La oms define tres modalidades: comunitaria, por conglomerados y esporádica. La primera corresponde a una difusión local masiva no necesariamente vinculada a cadenas de transmisión o a la aparición de múltiples agrupamientos no conectados entre

${ }^{18}$ A este respecto, habrá que precisar la existencia de posibles sesgos en los datos totales (de contaminación, muertes e índice de letalidad), generados por la escasa capacidad de los Estados de ambas regiones para realizar pruebas. A modo de ejemplo, cabe señalar que en el Caribe, al comienzo de la pandemia en la región (a mediados de marzo de 2020), el Carpha aumentó su capacidad de pruebas a 10000 , cuando inicialmente era de 3000 . Si se comparan las dos regiones, la tasa de pruebas respecto a la población total sigue siendo baja al 4 de enero de 2021, con sólo cinco Estados que superan el $10 \%$ de la población sometida a pruebas (Panamá, Belice, Bahamas, Barbados y Santa Lucía). Para los datos de las pruebas efectuadas por países, véase el cuadro 3 en el anexo. 
sí. Las transmisiones por conglomerados se refieren a difusiones localizadas en el tiempo y en el espacio. Por último, los casos esporádicos concuerdan con el tipo de propagación más bajo, es decir, mediante la aparición de casos importados o detectados localmente. ${ }^{19}$ Según esta tipología, al 23 de agosto de 2020 sólo cuatro Estados miembros de la Caricom experimentaban una propagación de tipo comunitario (entre ellos, Belice), tres de ellos tienen sólo casos esporádicos (Santa Lucía, San Cristóbal y Nieves y San Vicente y las Granadinas), un Estado no tiene ningún caso (Monserrat) y otros Estados ven el virus diseminarse por conglomerados. ${ }^{20}$ En América Central, el contagio sigue siendo comunitario para todos los países en la misma fecha, lo que prefigura una mayor vulnerabilidad al riesgo de difusión del virus.

Con el fin de limitar su propagación regional, los Estados miembros han aplicado numerosas medidas. Se pueden agrupar en cinco grandes categorías: restricción de la movilidad, distanciamiento social, medidas de salud pública, medidas socioeconómicas y confinamiento. ${ }^{21}$

Como lo sostienen Madhuyanti Murphy y sus coautores, en comparación con otros Estados del mundo, los de la Caricom adoptaron medidas tempranas. ${ }^{22} \mathrm{En}$ promedio, las primeras medidas de control de los desplazamientos hacia los territorios de la región se tomaron 27 días antes de la aparición del primer caso. El promedio es de cuatro días antes del primer caso para una muestra de países extranjeros (Alemania, Islandia, Italia, Nueva Zelanda, Singapur, Corea

19 Organización Panamericana de la Salud, ops, "Cumulative Confirmed and Probable COVID-19 Cases Reported by Countries and Territories in the Region of the Americas", https://ais.paho.org/phip/viz/COVID 19Table.asp (consulta del 25 de agosto de 2020).

${ }^{20}$ Loc. cit.

${ }^{21}$ Assessment Capacities Project (Acaps), “\#COVID 19: A global Joint Response", https://www.acaps.org/projects/covid19 (consulta del 22 de agosto de 2020).

22 Madhuvanti M. Murphy et al., art. cit. 
del Sur, Suecia, Reino Unido, Vietnam).${ }^{23}$ En cuanto al control de las circulaciones internas, los Estados de la Caricom respondieron en promedio nueve días después de la aparición del primer caso, frente a 15 en la misma muestra internacional. En la misma lógica, el control de las reuniones se inició, como término medio, un día antes de la aparición del primer caso, frente a los 29 días siguientes al primer caso para la segunda muestra. ${ }^{24}$ En consecuencia, los Estados de la Caricom han actuado con un promedio de tres a cuatro semanas de anticipación respecto de las respuestas de otros Estados del mundo.

En América Central, las primeras medidas que tomaron los gobiernos también fueron tempranas. En promedio, la primera medida nacional se adoptó 19.5 días antes de que apareciera el primer caso. Al igual que en el Caribe, no se puede subestimar el efecto de la explosión de la crisis sanitaria en Europa. Costa Rica y el Salvador se distinguen por la precocidad de su reacción. La primera medida nacional se aplica en esos dos Estados 46 y 55 días antes, respectivamente, de la aparición del primer caso confirmado. En América Central, no todas las primeras medidas estuvieron relacionadas con el control de la circulación. ${ }^{25}$ El Salvador es el único que intervino muy pronto en este ámbito (55 días). Costa Rica, Honduras, Guatemala y Nicaragua tomaron medidas relacionadas con la regularización de la salud. Belice intervino en materia de protección social (1 de marzo). Panamá tomó su primera medida en materia de educación (11 de marzo). Cuando sólo se observaba el control de la movilidad, la región centroamericana adoptó, en promedio, una reacción precoz de 2.6 días previos a la aparición del primer caso confirmado. Sin embargo, hay que precisar que esta media estuvo sesgada por el caso salvadoreño, que

${ }^{23}$ Loc. cit.

${ }^{24}$ Loc. cit.

25 Observatorio Regional Sica-Cavid 19, https://www.sica.int/coronavirus/observatorioSicaCOVID19 (consulta del 2 de octubre de 2020). 
estableció una medida anticipada 55 días antes del primer caso. Sin esta excepción salvadoreña, la centroamericana fue de 4.8 días después de la aparición del primer caso (o sea, parecida a la de los países extranjeros antes mencionados). Sólo El Salvador y Guatemala adoptaron el control de la movilidad antes de que se produjeran los primeros casos en Centroamérica. Los demás países aplicaron estas medidas entre tres (Costa Rica) y 13 días (República Dominicana).

Con estas medidas tempranas, la propagación del virus se logró controlar en ambos espacios regionales. Al 1 de septiembre, todos los Estados estaban por debajo del $5 \%$ de tasa de crecimiento diario del contagio (con excepción de Jamaica, con 11.5\%). Por lo tanto, partiendo de los valores absolutos de casos confirmados y fallecimientos (en comparación con otras partes del mundo) y del control de la propagación del virus, los Estados del Sica y la Caricom se posicionan a principios de septiembre de 2020 como experimentos de control y resistencia frente a la primera ola de la Covid-19.

Esta situación puede parecer paradójica al menos en dos aspectos: la alta vulnerabilidad de los Estados y su debilidad estructural, como ya se ha mencionado, y el enorme impacto de la crisis para los donantes tradicionales que ven reducidas sus capacidades de ayuda a las dos regiones. Aunque se trata de dos factores fundamentales para analizar las respuestas de los Estados del Sica y de la Caricom al Covid-19, ¿cómo explicar el control de la pandemia y esta experiencia de "buena gestión de crisis"?

INSTITUCIONES Y APOYOS EXTERIORES: LA VALORIZACIÓN DE LOS CONOCIMIENTOS TÉCNICOS REGIONALES

Mientras los Estados del Sica y de la Caricom apostaban por estrategias nacionales de prevención, con la notable excepción de Nicaragua, que mucho tiempo negó la peligrosidad 
del virus y sus efectos nacionales, ${ }^{26}$ las organizaciones regionales contribuyeron a la mitigación de los efectos directos e indirectos de la pandemia. Este buen desempeño de las políticas regionales contra la propagación del virus se debe, como veremos, a la interrelación de un factor de aprendizaje, vinculado con la historia de las dos regiones, en particular ante la gestión de crisis naturales y medioambientales, y el apoyo estructural de agentes exteriores canalizado por las organizaciones regionales. Elaboramos aquí un panorama región por región.

\section{América Central y el Sica}

En Centroamérica, se activó muy rápidamente el conjunto institucional regional, con un esfuerzo significativo de coordinación entre organismos regionales: la SE-Cepredenac (Secretaría Ejecutiva del Centro de Coordinación para la Prevención de los Desastres en América Central y República Dominicana), la sE-Comisca (Secretaría Ejecutiva del Consejo de Ministros de Salud de Centroamérica y República Dominicana), y la SG-Sica (Secretaría General del Sica), para la elaboración de un plan regional, titulado "Plan de contingencia". A partir del 20 de febrero, el Secretario General del Sica, Vinicio Cerezo (expresidente de Guatemala, 1986-1991), convocó a una reunión entre el Sica, la SE-Comisca y el oIRsA (Organismo Internacional Regional de Sanidad Agropecuaria). Esta reunión presentó el primer reporte de daños y constituyó un motor para la coordinación de los Estados miembros, al pedir la elaboración de un plan de trabajo común. Durante las semanas siguientes (principalmente en marzo), casi todas las organizaciones regionales sectoriales se sumaron al esfuerzo regional: Concadeco (Consejo Centroamericano de Protec-

${ }^{26}$ Wilfredo Miranda, "El Gobierno de Ortega minimiza los casos de la Covid-19 mientras crecen las alarmas en los hospitales", El País, 4 de mayo de 2020. 
ción del Consumidor) para garantizar el suministro y el control de precios; sE-Cosefin (Secretaría Ejecutiva del Consejo de Ministros de Hacienda o Finanzas) para formular solicitudes de ayuda directa o moratoria de deudas con las instituciones financieras internacionales (FMI, Banco Mundial); el Banco Centroamericano de Integración Económica (BCIE) para la asignación de fondos de emergencia; sE-Cepredenac para coordinar las unidades de respuesta humanitaria a la pandemia; la Secretaría de Integración Económica Centroamericana (Sieca) para ayudar a agilizar el comercio intrarregional (mecanismos de facilitación comercial, Declaración Única Centroamericana (Duca).

Esta activación de la arquitectura regional, que culminó con una reunión extraordinaria de jefes de Estado y de gobierno el 12 de marzo, constituye sin duda una primera secuencia de acción regional caracterizada por la aplicación de un proceso de concertación y coordinación con miras a la constitución de una respuesta propiamente regional. En esta secuencia, las instituciones regionales, bajo el impulso del SG Vinicio Cerezo, lograron promover el diálogo y el consenso en una fase desfavorable para el Sica. Recordemos que la crisis de Nicaragua en abril de 2018 y la deriva autoritaria de Daniel Ortega en la presidencia habían contribuido a desacelerar el proceso de diálogo regional. Además, cuando llegó la Covid-19, varias administraciones iniciaban su mandato. Así ocurrió en El Salvador con el presidente Nayib Bukele y en Guatemala, con Alejandro Giammattei. Por ello, en un momento en que la cooperación política regional era frágil o incluso estaba en declive, la creación de un consenso sobre el Plan de contingencia se consideró como un indicador de la buena actuación de las or.

En cuanto al ejercicio del liderazgo de la SG-Sica, reconocido por numerosos agentes (desde su gabinete hasta los ministerios sectoriales nacionales, pasando por las agencias regionales), no hay que subestimar el legado de la experiencia individual de Vinicio Cerezo, que ayudó a reactivar el diálogo regional en un periodo de conflictos civiles armados a finales 
de la década de 1980. No obstante, esta herencia no es sólo una cuestión individual, sino también colectiva dentro del Sica. La región centroamericana ha sido afectada con frecuencia por crisis de envergadura. El presidente panameño da fe de ello en el marco del lanzamiento del Plan de contingencia: "Todos hemos conocido grandes huracanes, grandes tormentas y, en definitiva, han pasado, y hemos tomado conciencia de ello. Esta pandemia también pasará y nos recuperaremos y saldremos de ella mucho más unidos". ${ }^{27} \mathrm{El}$ istmo guarda de manera especial la memoria de la catástrofe natural que se produjo en ocasión del paso del huracán Mitch en octubre de 1998. Indirectamente, esta crisis había favorecido la reactivación del regionalismo centroamericano a partir de la constatación de la impotencia y la impreparación de los Estados de la región. El Plan de reactivación sirvió de base y de fundamento para la elaboración de un diálogo renovado con los cooperantes, en particular con motivo del Grupo Consultivo de Madrid en 2001 y la consolidación de algunas instituciones encargadas de la gestión de la crisis, en especial la Cepredenac. ${ }^{28}$

La crisis de 1998 propulsó en el acercamiento de los cooperantes y las organizaciones regionales, que se convierten de facto en entidades canalizadoras y atrayentes de fondos de cooperación. En este periodo, se instauró un diálogo privilegiado con España y la Unión Europea (memoranda de entendimiento, estrategias y programas comunes, espacio de diálogo con la creación de comisiones mixtas), lo que dio lugar a una intensa consolidación institucional, a través de la burocratización, entre 2004 y 2013. De ahí se deriva la creación de un verdadero conocimiento regional para captar recursos externos, un conocimiento que se aplica ahora para hacer frente a la pandemia. ${ }^{29}$

27 SG-Sica, "Cortizo pone a disposición el Hub Sanitario para Centroamérica ante la emergencia del Coronavirus”, 12 de marzo de 2020, https: / www.sica.int/consulta/Noticia.aspx?Idn=121400\&idm=1 (consulta del 15 de octubre de 2020).

${ }^{28}$ Kevin Parthenay, op. cit.

${ }^{29}$ Loc. cit. 
Una vez que se validó el Plan de contingencia, se abrió otra secuencia en la que las or buscaron apoyo externo, especialmente financiero, para llevar a cabo las acciones del plan. Desde el 24 de marzo se organizó una reunión con los cooperantes (Organización Panamericana de la Salud (ops), Arbeiter-Samariter-Bund (AsB, Confederación de Trabajadores y Samaritanos de Alemania), oxfam, Agencia Suiza para la Cooperación y el Desarrollo (Cosude), Protección Civil de la UE, United Nations Office for Disaster Risk Reduction (UNDRR, Oficina de las Naciones Unidas para la Reducción del Riesgo de Desastres), United Nations Office for the Coordination of Humanitarian Affairs-Regional Office Latin America and the Caribbean (ochA-rolac, Oficina de las Naciones Unidas para la Coordinación de Asuntos Humanitarios-Oficina Regional para América Latina y el Caribe). Otros cooperantes tradicionales también entraron rápidamente en acción. Desde el 31 de marzo, Taiwán comenzó a intervenir con un fondo regional de emergencia Covid-19 de 4 millones de dólares para Belice, Guatemala, Honduras y Nicaragua (El Salvador, Panamá y Costa Rica reconocieron a la República Popular China y, por lo tanto, ya no tienen relaciones diplomáticas con Taiwán); donación de máscaras para Belice (13000 unidades) y Guatemala (180000 unidades), el 13 de abril; ayuda a las pequeñas y medianas empresas a través de Cenpromype (2 millones de dólares, 12 de mayo). El Development Bank of Latin America (CAF, Banco de Desarrollo de América Latina), que es el banco de desarrollo andino, proporcionó asistencia económica a Costa Rica ( 5 millones de dólares en fondos no reembolsables y una línea de crédito excepcional de 50 millones de dólares, el 31 de marzo). ${ }^{30}$ Corea del Sur donó 180000 pruebas (26000 por país). Ante

${ }^{30}$ Presidencia de la República de Costa Rica, "Banco CAF pone a disposición de Costa Rica y la región ayuda económica para el combate al Covid-19", 31 de marzo de 2020, https://www.presidencia.go.cr/comuni cados / 2020/03/banco-caf-pone-a-disposicion-de-costa-rica-y-la-regionayuda-economica-para-el-combate-al-covid-19/ (consulta del 2 de enero de 2021). 
la expansión del virus, la SG-Sica pidió la activación del "corredor humanitario centroamericano" para garantizar un retorno seguro de los ciudadanos que se encontraban en otro país. ${ }^{31}$ Además, se reasignaron fondos de cooperación de Estados Unidos, del Programa de Salud Global, de los Centros de Control y Prevención de Enfermedades, CDC por su sigla en inglés) para la compra de equipos (reactivos de laboratorio, máscaras, pruebas). Estas ayudas financieras, canalizadas por las OR, no deben soslayar el mantenimiento de las ayudas dirigidas directamente a los Estados centroamericanos, por ejemplo: de Taiwán para Belice (donaciones de máscaras); de Estados Unidos para Honduras (asistencia de 5.4 millones de dólares), El Salvador (6.6 millones de dólares) y Guatemala (8.4 millones de dólares), del FMI para El Salvador (389 millones de dólares de ayuda financiera de emergencia). .32

Desde un principio, el papel de la Cepredenac ha sido central para el establecimiento de la coordinación regional. Esta agencia regional para la prevención de desastres naturales ha trabajado principalmente para coordinar los esfuerzos regionales, en estrecha relación con la Comisca, para vincular las unidades de emergencia humanitaria, estructurar una

${ }^{31}$ Sistema de la Integración Centroamericana, Sica, "SICA pone en marcha el Plan de Contingencia Regional frente al Coronavirus por más de US\$1,900 millones", 12 de marzo de 2020, https://www.sica.int/noticias/sica-pone-en-marcha-el-plan-de-contingencia-regional-frente-al-coronavirus-por-mas-de-us-1-900-millones_1_121514.html (consulta del 2 de enero de 2021).

${ }^{32}$ Departamento de Estado de Estados Unidos, "U.S. Government Support to El Salvador, Guatemala, Honduras, and Mexico during the COVID-19 Pandemic", 11 de junio de 2020, https://www.state.gov/u-sgovernment-support-to-el-salvador-guatemala-honduras-and-mexico-du ring-the-covid-19-pandemic (consulta del 2 de octubre de 2020).

Fondo Monetario Internacional, FMI, "IMF Executive Board Approves a US\$389 Millones Disbursement to El Salvador to Address the COVID-19 Pandemic", 14 de abril de 2020, https:/ / www.imf.org/en/News/Articles/2020 /04/14/pr20155-el-salvador-imf-executive-board-approves-a-us-389-milli on-disbursement-to-address-covid-19 (consulta del 2 de octubre de 2020). 
campaña de comunicación regional y activar las alertas de emergencia en materia de salud pública (14 de marzo). La Cepredenac creó, además, el 17 de marzo, un equipo encargado de la instalación de una plataforma digital que integra los datos de la RM-GIRD (Red mesoamericana-Gestión Integral de los Riesgos de Desastres), ${ }^{33}$ con vistas a la creación de una "Plataforma de información y coordinación Sica-Covid-19". Esta acción conjunta de Sica Digital y Cepredenac se convirtió posteriormente en un "Observatorio Regional Sica-Covid19”. El caso de la Cepredenac es emblemático de la forma en que las or logran llevar a cabo una función de apoyo a la acción de los Estados, y de la medida en que los instrumentos burocráticos están consolidados por las propias oR, a través de la centralización de los datos de salud pública. Las oR disponen así de la técnica, una técnica que dicta las medidas que deben adoptarse y el marco de acción. En este sentido, se imponen en los escenarios de crisis, como el de la Covid-19, en cuanto sustitutos burocráticos para los Estados miembros.

En otro registro, las instituciones regionales ayudaron a los Estados a obtener subvenciones o ajustes financieros de las instituciones financieras internacionales (IFI). En el primer caso, el Banco Centroamericano de Integración Econó-

${ }^{33}$ En la Cumbre de San Salvador, celebrada el 15 de junio de 2001, el Mecanismo de diálogo y concertación de Tuxtla integra un componente de "Gestión integral de los riesgos" en el Proyecto de Integracion y Desarrollo de Mesoamérica. Sobre la base de los datos del Atlas de las amenazas en Centroamérica, elaborado por Cepredenac, se está creando un sistema de información territorial mesoamericano (SMIT). Este sistema se convirtió en marzo de 2014 en el "RM-GIRD" sobre el que Cepredenac se basó para la gestión de la crisis sanitaria. Desde su creación, el BID ha financiado la creación de estos instrumentos de recopilación de datos. El SMIT costó 1.5 millones de dólares y el BID participó con 700000 dólares. En la segunda fase, que se convirtió en RM-GIRD, el BID financió nuevamente 600000 dólares en el marco del programa "Iniciativa Bienes Públicos Regionales". Red Mesoamericana para la Gestión Integral de Riesgos, RMIGR, "Iniciativa Bienes Públicos Regionales", https://rmgir.proyectomesoamerica.org (consulta del 2 de octubre de 2020). 
mica (BCIE) desempeñó un papel nada desdeñable al validar una solicitud de los Estados miembros de ampliación del fondo de emergencia de 250000 a 1 millón de dólares, así como la activación de una línea de crédito excepcional de 50 millones de dólares. Por otra parte, un equipo de economistas compuesto por miembros de la Sieca, BCIE, SE-CMCA y SECosefin emprendieron un trabajo conjunto con el Banco Mundial y el Banco Interamericano de Desarrollo (BID) para obtener un apoyo técnico a largo plazo (posterior a la primera ola de contaminación) y la reestructuración de la deuda (bajo el impulso de la Presidencia pro tempore hondureña del Sica y de Costa Rica). ${ }^{34}$ El 17 de marzo de 2020, el seCosefin se reunió con el FMI para formular, en nombre de los Estados del Sica, una solicitud de asistencia a los países de la región. El FMI, en cambio, respondió que quería privilegiar las relaciones bilaterales. Una petición similar dirigida al Banco Mundial fue transmitida al G-20 (para su dictamen) y, finalmente, tanto el Banco Mundial como el FMI aceptaron una suspensión temporal del pago de la deuda para los países miembros de la Asociación Internacional de Fomento (AIF), es decir, Honduras y Nicaragua. ${ }^{35}$

Las instituciones regionales también fueron beneficiosas para los Estados miembros en cuanto al acceso preferencial a los mercados farmacéuticos mundiales. Ante la aparición de esta crisis sanitaria, el uso de una "negociación conjunta centroamericana” excepcional, cuya activación se solicitó a partir del 12 de marzo y se hizo efectiva el 21 del mismo mes, facilitó el acceso a material médico con tarifas preferentes

34 Observatorio Regional Sica-Covid-19, "Informes Centroamérica y República Dominicana unidos contra el Coronavirus (COVID-19)", https://www.sica.int/consulta/documentos_1615_12_1.html (consulta del 2 de octubre de 2020).

35 Banco Mundial, "Covid-19: Initiative de suspension du service de la dette”, 12 de enero de 2021, https://www.banquemondiale.org/fr/to $\mathrm{pic} / \mathrm{debt} / \mathrm{brief} / \mathrm{covid}-19$-debt-service-suspension-initiative (consulta del 12 de enero de 2021). En el Caribe, Dominica, San Vicente y las Granadinas, Granada, Guyana, Haití y Santa Lucía están interesados. 
(batas de protección, reactivos). La negociación conjunta centroamericana es un instrumento que se ha impuesto desde 2009 como la historia de éxito del regionalismo centroamericano al promover un acceso amplio a los mercados farmacéuticos extranjeros, logrando precios reducidos a través de pedidos regionales (ahorros de 61000 millones de dólares entre 2009 y 2018, con una rebaja promedio del 25 al $30 \%$ en el precio de los medicamentos). ${ }^{36}$ Durante la crisis, la negociación conjunta se impuso como una "buena práctica" y comenzó a difundirse a escala continental. Fue presentada el 24 de abril ante la Organización de Estados Americanos (oEA) y el 30 de abril ante la Asociación de Estados del Caribe (AEC). Por otra parte, Ecuador ha solicitado su adhesión al mecanismo.

Como consecuencia de esta experiencia de difusión de una buena práctica centroamericana, una última secuencia identificada en la gestión regional de la pandemia fue la construcción de un discurso de eficacia y éxito en la gestión de la crisis sanitaria frente al exterior. Desde fines de abril, las instituciones regionales centroamericanas han compartido su experiencia hacia el exterior con incontables "webinars". El objetivo de esta estrategia de comunicación institucional es dar testimonio del desempeño institucional y procurar (re) legitimar la or en un contexto de fragilidad en la cooperación.

\section{El Caribe y la Caricom}

En la región del Caribe, al igual que en Centroamérica, se encuentra esta mezcla de aprendizaje sobre gestión de crisis

36 María de los Ángeles Campos de Murillo, "Negociación conjunta de precios y compra de medicamentos para Centroamérica y República Dominicana-Una mirada desde la perspectiva de salud internacional", SEComisca, 2016, https:/ / www.paho.org/els/index.php?option=com_docm an\&view=download\&alias=1733-negociacion-conjunta-comisca-plsifinal\&Itemid=292 (consulta del 24 de enero de 2021). 
y financiación externa de la Caricom, caracterizada por la falta de transparencia presupuestaria; ${ }^{37}$ se conocen, en cambio, las sumas invertidas por los agentes externos en las instituciones regionales de salud. Cuando comenzó a funcionar la Caribbean Public Health Agency (Carpha, Agencia de Salud Pública del Caribe), la Unión Europea aportó 2 millones de dólares, Canadá 0.8 millones, Reino Unido 0.2 millones y el CDC, 5 millones. Esta financiación externa fue fundamental para la activación del organismo regional, siete años después del mandato formulado por los jefes de Gobierno mediante la declaración de Needham Point, emitida durante la 28 Reunión de Jefes de Gobierno, celebrada en Barbados. $\mathrm{Al}$ establecer el mandato, la Organización Panamericanaca de la Salud (ops), oficina regional de la Organización Mundial de la Salud (oms), ya había prestado apoyo técnico y experiencia a través de su exdirectora, Dra. Mirta Roses.

La ambición de formular una política sanitaria regional no es nada nuevo en la Caricom. En la Declaración de Nassau de 2001 se destacó el lema "la salud de la región es el bienestar de la región”. Como seguimiento de esta declaración, la decisión de crear la Carpha se tomó algunos años después con la Declaración de Needham Point. En la reunión que desembocó en esta declaración, el asesor de la Carpha y exasistente del SG-Caricom, Dr. Edward Green, dijo: "Por primera vez, el Caribe tendrá una voz única para representar nuestra región en el sector de la salud a nivel mundial. Nos ayudará a realizar la visión de la Declaración de Nassau de 2001". 38 Sin embargo, esta agencia no habría de entrar en funciones sino hasta 2013 y, no obstante, esta activación prefigura una nueva dinamización de la acción regional en materia de salud. En la 17 Reunión Especial de Jefes de Gobierno de la Caricom, en 2014, las autoridades de la región se pusieron

37 Anne Marie Hoffman, art. cit.

38 "Caricom to establish Health Agency", Caribbean Journal, 15 de junio de 2011, https://www.caribjournal.com/2011/06/15/caricom-to-establish-regional-health-agency (consulta del 2 de octubre de 2020). 
de acuerdo para la creación de un Regional Coordination Mechanism on Ebola (RCME, o Mecanismo de Coordinación regional sobre el Ébola). El espectro de este mecanismo se expande más adelante, convirtiéndose en un Regional Coordination Mechanism on Health Security (RCMHS, Mecanismo de Coordinación Regional sobre Seguridad Sanitaria). Estas iniciativas institucionales nos recuerdan que la región del Caribe sufre desde hace mucho tiempo de escenarios de crisis de salud pública. La región enfrenta regularmente epidemias (ébola, dengue, zika, chikunguña, etcétera).

A partir de estos hechos, se entiende mejor por qué se tomaron tan velozmente las medidas de alerta y las respuestas al virus. Desde el 21 de enero, el Carpha Medical Microbiology Laboratory (CMML, Laboratorio de Microbiología Médica), con sede en Trinidad y Tobago, trabajó en estrecha colaboración con la ops para el desarrollo de capacidades de los laboratorios de la región. El organismo regional ha seguido las recomendaciones de la oms y ha colaborado con los asociados internacionales para desarrollar pruebas, y a la vez ha dado un seguimiento riguroso de la evolución de la situación sanitaria regional. A raíz de los primeros casos positivos confirmados, el 25 de enero se instaló un Incident Management Team (IMT, equipo de gestión de incidentes) para coordinar la respuesta regional. A este respecto, se prepararon y pusieron a disposición de los Estados comunicados de prensa que sirvieron de guías de comunicación a nivel nacional. ${ }^{39}$ El Carpha elaboró guías para los viajeros en circulación en los Estados miembros, tras haber reunido a epidemiólogos, directores de laboratorios y médicos. Los jefes de Gobierno celebraron una cumbre de emergencia el 4 de febrero de 2020 para establecer una respuesta regional. También se creó un grupo de asesoría técnica para proporcionar una guía de gestión de casos de contagios y un plan de redes

${ }^{39}$ Agencia de Salud Pública del Caribe, Carpha, "Coronavirus Disease (COVID-19)", https://carpha.org/What-We-Do/Public-Health/Novel-Coronavirus (consulta del 2 de octubre de 2020). 
sociales para apoyar una estrategia de comunicación regional. Desde su creación y hasta septiembre de 2020, el IMT ha completado tres informes regionales por semana con el fin de elaborar un panorama común de información. ${ }^{40}$

A partir de ahí, como en Centroamérica, se movilizó progresivamente la arquitectura regional: la Caricom Implementation Agency for Crime and Security (ImPAcs, Agencia de Implementación para el Crimen y la Seguridad de Caricom), para generalizar la identificación de los viajeros procedentes de China y otros países afectados; el Regional Security System (Rss, Sistema de Seguridad Regional) para el transporte de muestras. También se creó un Joint Regional Communication Center (JRcc, Centro Regional Conjunto de Comunicación) que conecta la Unidad de Comunicación de la Carpha con la Red Regional de Comunicación de la Salud para promover y actualizar las actividades en la región y facilitar la circulación a la entrada o salida de los puertos y aeropuertos. Por otra parte, a partir de finales de febrero, la Carpha comenzó a trabajar en estrecha colaboración con el Caribbean Disaster Emergency Management Agency (CDEMA, Agencia de Gestión de Emergencias en situación de Desastre del Caribe) y con el Council of Human and Social Development del Caricom (CHSD, Consejo de Desarrollo Humano y Social de la Caricom). La CDEMA, como ya se ha indicado, contribuyó ampliamente a la coordinación logística a escala regional, como complemento de la gestión "salud" llevada a cabo por la Carpha y la ops (Core Coordination Cell for Health o Célula esencial de coordinación para la salud). Las dos primeras organizaciones participaron activamente en la segunda Cumbre Extraordinaria de jefes de Gobierno de la Caricom, celebrada en Barbados el 1 de marzo de 2020.

${ }^{40}$ Victoria Cruickshank-Taylor, "Carpha Covid-19 Response”, Carpha, 14 de octubre de 2020, https://carpha.org/More/Media/Articles/Arti cleID/366/CARPHA-COVID-19-Response (consulta del 25 de enero de 2021). 
Siguiendo una dinámica similar a la de Centroamérica, una vez que se puso en marcha la coordinación regional, se impuso una estrategia de apertura hacia el exterior. El 6 de marzo de 2020, partiendo de las recomendaciones de Carissa Etienne, directora de la ops, el Caribe pasó a un nivel de alerta "muy elevado". En este estadio, la reacción de las instituciones regionales y de los Estados miembros fue formar una red de asociados extranjeros, especialmente de Canadá, Estados Unidos y Gran Bretaña, socios históricos. El 6 de marzo se celebró una reunión del "Caribbean Development Partners Group”, en la que participó la Carpha. De hecho, durante las semanas que siguieron a la puesta en marcha de la arquitectura regional de respuesta a la crisis sanitaria, el apoyo externo cobró una dimensión estratégica.

Dada la escasez de agentes reactivos a partir del 5 de abril de 2020, la UE intervino concediendo una ayuda financiera de 8.6 millones de dólares para obtener los productos necesarios. Canadá también proporcionó apoyo logístico mediante la reasignación de más de 400000 dólares (inicialmente para el proyecto CDEMA) a la construcción de un centro logístico regional integrado (coordinado por el CDEMA), equivalente para el Caribe al hub panameño para Centroamérica. Sus operaciones han recibido el apoyo del Programa Mundial de Alimentos (PMA).$^{41} \mathrm{El} 13$ de agosto de 2020, los Estados de la Caricom recibieron una donación de equipo médico de la oms, de la Fundación Jack Ma y de los Emiratos Árabes Unidos (EAU). La CDEMA efectuó la distribución a los Estados de la región desde el centro logístico regional de Barbados, por un valor de más de 700000 dólares. La solicitud de apoyo a la oms había sido formulada por la primera ministra de Barbados, Mia Mottley, también en su calidad de presidenta de la Caricom. Entre las ayudas extranjeras, la República

41 "Caraïbes. La Caricom coordonne la fourniture de fournitures essentielles de COVID-19 aux États membres", Carib Creole News, 12 de agosto de 2020, http://www.caraibcreolenews.com/index.php/caraibes/ item/1 7550-caraibes-la-caricom-coordonne-la-fourniture-de-fourni tures-essenti elles-de-covid-19-aux-etats-membres (consulta del 2 de octubre de 2020). 
Popular China también proporcionó asistencia médica (15000 paquetes de pruebas y 30000 mascarillas). Cabe señalar asimismo el importante papel del Banco de Desarrollo del Caribe (CDB, por sus siglas en inglés), que utilizó su Fondo Especial para el Desarrollo para adquirir equipo médico con una base regional común a fin de beneficiarse de la economía de escala. Si bien la dependencia respecto a los actores externos sigue siendo persistente, aquí aparece una señal tímida de fortalecimiento del papel de las or en la creación de bienes comunes regionales.

\section{Covid-19: Conveniencia de (RE) Legitimación de los REGIONALISMOS}

Entre los aciertos de las instituciones regionales, podrán identificarse las medidas excepcionales de ayuda que pudieron haber contribuido a apoyar a los Estados miembros directamente, mediante fondos no reembolsables (extensión de los fondos de emergencia por el BCIE) o mediante financiaciones indirectas que faciliten el acceso a los mercados farmacéuticos a costo reducido (negociación conjunta, $\mathrm{CDB}$ ). Esto refleja el comienzo de una evolución potencialmente importante de los modelos regionales que hasta ahora se habían estructurado en torno a esquemas orientados hacia los recursos externos. La activación de los recursos propios y la consolidación de instrumentos que favorezcan las economías de escala son elementos de legitimación de las organizaciones regionales y, en particular, de sus intervenciones más pragmáticas, las de las ganancias y beneficios económicos. Por otra parte, cabe señalar que, en la fase inicial de elaboración de las respuestas regionales, las organizaciones trabajaron en un contexto de despolitización deliberada por parte de los Estados (en particular en Centroamérica, ante la situación conflictiva en Nicaragua), dejando un lugar preponderante a las dimensiones técnicas de gestión de la crisis. Esta orientación hacia la técnica contribuyó a la producción de 
bienes colectivos regionales (datos e información, material, peritajes, etcétera) que han influido positivamente en la legitimidad de los órganos regionales, a menudo despreciados por una eficacia relativa debido a la falta de voluntad política. El imperativo de prevenir y anticipar los riesgos de expansión pandémica ha favorecido en gran medida este predominio de la técnica sobre la política y, por consiguiente, cierta tendencia a la despolitización de las organizaciones regionales durante la crisis sanitaria.

Además, las dos organizaciones regionales se han caracterizado por un modelo de gestión específico. Una característica central de la gestión de la Covid-19, como problemática de salud pública global, fue su percepción a través del prisma de la gestión de "crisis" o "catástrofes"/"desastres". En los casos en que las organizaciones sectoriales de salud podrían haber intervenido solas (Comisca para Centroamérica y Carpha para Caricom), una de las claves de su buen desempeño fue la activación de los organismos especializados en gestión de desastres y emergencias (Cepredenac para Centroamérica, CDEMA para el Caribe). Esta orientación no sólo destaca el uso de los principales conocimientos técnicos de las or, sino también el hecho de que se han convertido en sustitutos burocráticos de los Estados de la región. En materia de control territorial (apoyo de IMPAcs en el Caribe), de recolección de datos territoriales y epidémicos (Cepredenac, vía RM-GIRD en Centroamérica), los Estados dependen de los datos procedentes de estos instrumentos regionales para la aplicación de sus acciones. La experiencia técnica de las oR, apoyada o no por las organizaciones internacionales, en contextos regionales en que los Estados son mayoritariamente débiles y vulnerables, compensa la falta de consolidación de órganos burocráticos a nivel nacional. Históricamente, la importancia de los actores externos y su financiación explica esta diferencia en las habilidades de organización. ${ }^{42}$

42 Para Centroamérica, véase a este respecto Kevin Parthenay, op. cit., capítulos 7 y 8 . 
Si bien el impacto reducido de la crisis sanitaria es un indicador del desempeño de la gestión de los Estados de la Caricom y el Sica, constituye una señal positiva para el regionalismo. Esta crisis, que se produjo en un contexto de debilitamiento de las cooperaciones regionales y multilaterales en el continente -y en los dos espacios regionales estudiados-, no pudo contra la concertación y la coordinación regionales. En un contexto que se ha visto dificultado por tensiones políticas a las que se ha sumado la crisis sanitaria, o por cambios políticos (dificultades de gestión administrativa), las or han logrado imponer sus conocimientos técnicos y promover una armonización de las prácticas para luchar contra el virus. Esta constatación no impedirá observar la persistencia de particularidades nacionales o de obstáculos a la armonización completa. En efecto, las normas diferentes en Honduras impidieron el otorgamiento de material médico (máscaras) por Taiwán. En Costa Rica, se promovió una plataforma específica a escala mundial (C-TAP) ${ }^{43}$ sin el apoyo de sus vecinos centroamericanos. Sin embargo, la naturaleza y las capacidades de los Estados miembros de los dos conjuntos regionales, así como las ventajas comparativas que ofrece el recurso a las oR, crearon una ventana de oportunidad para el regionalismo. Desde esta perspectiva, la crisis sanitaria se ha presentado como un vector de legitimación o relegitimación de las or en un momento de cuestionamiento profundo.

${ }^{43}$ El objetivo de la Plataforma es recopilar, en un solo lugar, los compromisos asumidos en el marco del llamamiento a la acción de solidaridad para compartir voluntariamente los conocimientos, la propiedad intelectual y los datos relacionados con la tecnología de la salud Covid-19. Véase Organización Mundial de la Salud, oms, "COVID-19 Technology Access Pool", https://www.who.int/emergencies/diseases/novel-corona virus-2019/global-research-on-novel-coronavirus-2019-ncov/covid-19-te chnology-access-pool (consulta del 2 de febrero de 2021). 


\section{Conclusión}

El estudio del Sica y de la Caricom ante la crisis de la Covid-19 pone de relieve, ante todo, la revitalización de estos dos regionalismos. El Sica y la Caricom, criticados frecuentemente por su inacción, inercia e incluso inutilidad-debido principalmente a la falta de voluntad política-, no sólo han actuado al lado de los Estados, sino que también los han acompañado en la crisis y han sido productores de bienes públicos regionales.

En el momento mismo en que se consideraba que los dos conjuntos regionales estaban viviendo una secuencia de debilitamiento o decadencia, la crisis constituyó un vector de revitalización. No se trata de un caso aislado, como hemos visto, sus historias regionales están llenas de otros casos semejantes. Sin embargo, su singular legado ha constituido una fuerza para hacer frente a la pandemia, gracias a los conocimientos técnicos acumulados y a los mecanismos institucionales existentes. Aunque la muerte de estas organizaciones regionales haya sido escenificada muchas veces, la crisis de la Covid-19 marcó la revitalización de los regionalismos centroamericano y caribeño. ${ }^{44}$

Otra lección que se puede extraer de esta secuencia es la eficacia de las cooperaciones funcionales que presagian un retorno al funcionalismo de la génesis. En efecto, los principales valores agregados fueron extraídos de economías de escala realizadas a través de herramientas burocráticas. Lo demuestran el éxito y las emulaciones de la negociación conjunta centroamericana. Si bien esta práctica tiende a extenderse más allá de América Central, simboliza un regreso al funcionalismo y puede presagiar el desarrollo de una dinámica de "spill-over" (efecto de derrame) hacia otros sectores. Dado que la negociación conjunta de productos farmacéuticos ha beneficiado a la región, a los Estados miembros y, en

${ }^{44}$ José Briceño-Ruiz y Andrés Puntigliano Rivarola (eds.), Regionalism in Latin America. Agents, Systems and Resilience, Abingdon, Routledge, 2020. 
última instancia, a los ciudadanos centroamericanos, su extensión a otros productos y sectores está al alcance de la mano. Queda por verse si el Caribe, por su parte, seguirá este modelo mediante una ampliación del intercambio institucional durante la crisis.

El 20 de julio de 2020, Helen Royer declaró ante los médicos del Caribe "De manera tal vez sorprendente para el mundo -pero no para nosotros los caribeños- nuestra región ha resurgido de pie de la primera ola". ${ }^{45}$ Aunque América Central puede compartir esta conclusión, quedan otros pendientes no menores, en particular la recuperación económica. Si bien la primera ola de la Covid-19 ha sido menos costosa en términos de vidas humanas para ambas regiones, las consecuencias socioeconómicas pueden ser más duraderas y dramáticas. Así pues, se plantea la cuestión de si, fuera de las situaciones de crisis y de emergencia sanitaria, las organizaciones regionales podrán mantener el diálogo regional, promover la armonización de las prácticas y, sobre todo, resistir las tentaciones de repliegue proteccionista en los Estados de ambas regiones. Si el Sica y la Caricom logran cumplir esta tarea, serán verdaderamente ejemplos de superación de los obstáculos y debilidades del multilateralismo regional en América Latina.

Por último, habrá que identificar algunas limitaciones inherentes a este análisis, que deben servir para alimentar futuras exploraciones empíricas y más amplias, que se beneficiarán de forma particular de la colaboración con especialistas en epidemiología y en salud pública. La primera se refiere al acceso a los datos que, en la fase de la investigación, se pusieron parcialmente a disposición, cuando existían y estaban consolidados. Esto es especialmente cierto en el caso de las cuestiones relativas a la mortalidad o a la aceleración

45 Dionne Bautista, "CMOS Told not to Neglect Other Health Issues Plaguing the Caribbean”, Loop, 20 de julio de 2020, https://www.loop newscaribbean.com/content/cmos-told-not-neglect-other-health-issuesplaguing-caribbean (consulta del 20 de enero de 2021). 
pandémica en ambas regiones, las dos en estrecha relación con el desafío de que existieran capacidades de aplicar pruebas (tasa de pruebas). En otras palabras, en la situación actual, hay que ser consciente de posibles sesgos debidos a la no detección de casos de contaminación o muerte vinculados a la Covid-19. Si estos puntos de orden metodológico han significado retos en una fase temprana de la pandemia, suponiendo que los datos puedan consolidarse algún día, no han impedido sin embargo formular un análisis de las reacciones tempranas de las organizaciones regionales centroamericanas y caribeñas y de sus interacciones con los Estados miembros. En consecuencia, la extensión temporal y geográfica del marco analítico propuesto en este artículo contribuirá, en términos generales, al estudio del regionalismo en las Américas, invitando a realizar evaluaciones comparativas del desempeño de sus Estados y organismos multilaterales en situaciones de crisis, ya sean sanitarias o de otro tipo.

\section{REFERENCIAS BIBLIOGRÁFICAS}

Agostinis Giovanni y Kevin Parthenay, "Exploring the Determinants of Regional Health Governance modes in the global South: A Comparative Analysis of Central and South America”, Review of International Studies (en proceso de revisión).

Assessment Capacities Project (Acaps), “\#COVID 19: A Global Joint Response", https://www.acaps.org/projects/covid19 (consulta del 22 de agosto de 2020).

Banco Mundial, "Covid-19: Initiative de suspension du service de la dette", 12 de enero de 2021, https:/ / www.banquemondiale. org/fr/topic/debt/brief/covid-19-debt-service-suspensioninitiative (consulta del 12 de enero de 2021).

Bautista, Dionne, "CMOS Told not to Neglect Other Health Issues Plaguing the Caribbean”, Loop, 20 de julio de 2020, https:/ / www.loopnewscaribbean.com/content/cmos-told-not-neglectother-health-issues-plaguing-caribbean (consulta del 20 de enero de 2021). 
Briceño-Ruiz, José y Andrés Puntigliano Rivarola (eds.), Resilence of Regionalism in Latin America and the Caribbean: Development and Autonomy, Basingstoke, Palgrave Macmillan, 2013.

Briceño-Ruiz, José y Andrés Puntigliano Rivarola (eds. ), Regionalism in Latin America. Agents, Systems and Resilience, Abingdon, Routledge, 2020.

Byron, Jessica, "Summitry in the Caribbean Community: A fundamental Feature of Regional Governance", en Mace Gordon et al. (eds.), Summits and Regional Governance. The Americas in Comparative Perspective, Nueva York, Routledge, 2016, pp. 114-131.

"Caraïbes. La Caricom coordonne la fourniture de fournitures essentielles de COVID-19 aux États membres", Carib Creole News, 12 de agosto de 2020, http:/ / www.caraibcreolenews.com/index. $\mathrm{php} /$ caraibes/item/17550-caraibes-la-caricom-coordonne-lafourniture-de-fournitures-essentielles-de-covid-19-aux-etatsmembres (consulta del 2 de octubre de 2020).

Agencia de Salud Pública del Caribe, Carpha, "Coronavirus Disease (COVID-19)", https:/ / carpha.org/What-We-Do/Public-Health/ Novel-Coronavirus (consulta del 2 de octubre de 2020).

"Caricom to establish Health Agency", Caribbean Journal, 15 de junio de 2011, https://www.caribjournal.com/2011/06/15/cari com-to-establish-regional-health-agency/ (consulta del 2 de octubre de 2020).

Campos de Murillo, María de los Ángeles, "Negociación conjunta de precedentes y medidas para Centroamérica y República Dominicana-una milagrada desde la perspectiva de salud internacional", sE-Comisca, 2016, https://www.paho.org/els/index. php?option=com_docman\&view=download\&alias=1733-nego ciacion-conjunta-comisca-plsi-final\&Itemid=292 (consulta del 24 de enero de 2021).

Comisión Económica para América Latina, Cepal, El regionalismo abierto en América Latina y el Caribe: la integración económica al servicio de la transformación productiva con equidad, Santiago, 1994.

Comunidad del Caribe, Caricom, "Brief on Caricom Relations with International Development Partners", 2016, https://caricom. org/Brief\%20on\% 20Caricom\% 20\%20Relations\%20with\%20 IDPs.pdf (consulta del 2 de octubre de 2020). 
Cruickshank-Taylor, Victoria, "Carpha Covid-19 Response", Carpha, 14 de octubre de 2020, https:/ / carpha.org/More/Media/ Articles / ArticleID/366/CARPHA-COVID-19-Response (consulta del 25 de enero de 2021).

Dabène, Olivier, Politics of Regional Integration in Latin America, Nueva York, Palgrave Macmillan, 2009.

Dunkley-Malc, Jascene, "Antiguan Government Establishes 'Travel Bubble' for Caribbean Travelers”, Caricom Today, 10 de julio de 2020, https://today.caricom.org/2020/07/10/antiguan-go vernment-establishes-travel-bubble-for-caribbean-travelers / (consulta del 2 de octubre de 2020).

Fondo Monetario Internacional, FMI, "IMF Executive Board Approves a US\$389 Millones Disbursement to el Salvador to Address the COVID-19 Pandemic", 14 de abril de 2020, https:// www.imf.org/en/News/Articles/2020/04/14/pr20155-el-sal vador-imf-executive-board-approves-a-us-389-million-disburse ment-to-address-covid-19 (consulta del 2 de octubre de 2021).

Hooghe, Liesbet y Gary Marks, "Types of Multi-Level Governance", European Integration online Papers (EIoP), vol. 5, núm. 11, 12 de octubre de 2001, http://dx.doi.org/10.2139/ssrn.302786

Hoffman, Anne Marie, "The Finances of the Caribbean Community (Caricom)", en Frank Mattheis y Ulf Engel (eds.), The Finance of Regional Organisations in the global South: Follow the Money, Abingdon, Routledge, 2020.

Mattheis, Frank y Ulf Engel (eds.), The Finance of Regional Organisations in the global South: Follow the Money, Abingdon, Routledge, 2020.

Murphy, Madhuvanti M. et al., "Covid-19 Containment in the Caribbean: The Experience of Small Island Developing States", Research in Globalization, núm. 2, 2020, pp. 1-9.

Observatorio Regional Sica-Covid 19, https://www.sica.int/coro navirus/observatorioSicaCOVID19 (consulta del 2 de octubre de 2020).

Observatorio Regional Sica-Covid-19, "Informes Centroamérica y República Dominicana unidos contra el Coronavirus (COVID19)", https://www.sica.int/consulta/documentos_1615_1 2_1. html (consulta del 2 de octubre de 2020). 
Organización Mundial de la Salud, oms, "COVID-19 Technology Access Pool”, https://www.who.int/emergencies/diseases/ novel-coronavirus-2019/global-research-on-novel-coronavirus2019-ncov/covid-19-technology-access-pool (consulta del 2 de febrero de 2021).

Organización Panamericana de la Salud, ops, "Cumulative Confirmed and Probable COVID-19 Cases Reported by Countries and Territories in the Region of the Americas", https://ais. paho.org/phip/viz/COVID19Table.asp (consulta del 25 de agosto de 2020).

Parthenay, Kevin, "Integración regional en Centroamérica. Una sociología política del cambio (1991-2012)", tesis doctoral en Ciencia Política, París, Sciences Po, 2013.

Parthenay, Kevin, "Autonomy in Latin American Regional Bureaucacies: The Role and Place of the General Secretarias", Critique Internationale, vol. 87, núm. 2, 2020, pp. 153-174.

Presidencia de la República de Costa Rica, "Banco CAF pone a disposición de Costa Rica y la región ayuda económica para el combate al COVID-19", 31 de marzo de 2020, https:/ / www. presidencia.go.cr/comunicados/2020/03/banco-caf-pone-adisposicion-de-costa-rica-y-la-region-ayuda-economica-parael-combate-al-covid-19/ (consulta del 2 de enero de 2021).

Red Mesoamericana para la Gestión Integral de Riesgos (RMIGR), "Iniciativa Bienes Públicos Regionales", https://rmgir.proyectomesoamerica.org (consulta del 2 de octubre de 2020).

se-Comisca, Informe de Gestión Financiera 2015-2016, San Salvador, 2016.

sG-Sica, "Cortizo pone a disposición el Hub Sanitario para Centroamérica ante la emergencia del coronavirus", 12 de marzo de 2020, https: / / www.sica.int/consulta/Noticia.aspx?Idn=1214 00\&idm=1 (consulta del 15 de octubre de 2020).

Sistema de la Integración Centroamericana, Sica, "SICA pone en marcha el Plan de Contingencia Regional frente al Coronavirus por más de US $\$ 1,900$ millones", 12 de marzo de 2020, https://www.sica.int/noticias/sica-pone-en-marcha-el-plan-decontingencia-regional-frente-al-coronavirus-por-mas-de-us- 
1-900-millones_1_121514.html (consulta del 2 de enero de 2021).

Telias, Diego y Francisco Urdíñez, “China's Foreign Aid Determinants: Lessons from a Novel Dataset of the Mask Diplomacy during the COVID-19 Pandemic", documento de trabajo inédito, doi: 10.13140/RG.2.2.27199.53929

Departamento de Estado de Estados Unidos, "U.S. government Support to el Salvador, Guatemala, Honduras, and Mexico during the COVID-19 Pandemic”, 11 de junio de 2020, https:// www.state.gov/u-s-government-support-to-el-salvador-guatema la-honduras-and-mexico-during-the-covid-19-pandemic/ (consulta del 2 de octubre de 2020).

Wilfredo, Miranda, "El Gobierno de Ortega minimiza los casos de la Covid-19 mientras crecen las alarmas en los hospitales", El País, 4 de mayo de 2020. 


\section{Anexo 1 \\ Cuadro 3 \\ Pruebas Covid-19 realizadas por los Estados miembros del Sica y de la Caricom}

\begin{tabular}{|c|c|c|c|c|}
\hline & & Población & $\begin{array}{c}\text { Pruebas realizadas } \\
\text { (al } 4 \text { de enero de 2021) }\end{array}$ & $\begin{array}{c}\% \text { de la } \\
\text { población total }\end{array}$ \\
\hline \multirow{8}{*}{ 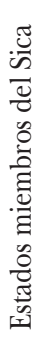 } & República Dominicana & 10226149 & 879918 & 8.60 \\
\hline & Costa Rica & 5003402 & 495225 & 9.90 \\
\hline & Panamá & 4160016 & 1332023 & 32.02 \\
\hline & Honduras & 9181487 & 308510 & 3.36 \\
\hline & Guatemala & 18065725 & 642654 & 3.56 \\
\hline & Nicaragua & 6460229 & n.d. & \\
\hline & El Salvador & 6641842 & 631180 & 9.50 \\
\hline & Belice & 398050 & 59978 & 15.07 \\
\hline \multirow{14}{*}{ 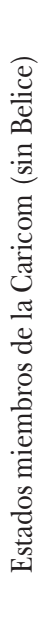 } & Antigua y Barbuda & 104084 & 6651 & 6.39 \\
\hline & Bahamas & 399421 & 52840 & 13.23 \\
\hline & Barbados & 285389 & 70257 & 24.62 \\
\hline & Dominica & 74679 & 6618 & 8.86 \\
\hline & Granada & 115465 & 6781 & 5.87 \\
\hline & Guyana & 752208 & 38622 & 5.13 \\
\hline & Haití & 11591279 & 42080 & 0.36 \\
\hline & Jamaica & 2728864 & 139878 & 5.13 \\
\hline & Monserrat & 5343 & nc & \\
\hline & Santa Lucía & 178696 & 19814 & 11.09 \\
\hline & San Cristóbal y Nieves & 56345 & 5593 & 9.93 \\
\hline & San Vicente y las Granadinas & 110049 & nc & \\
\hline & Suriname & 598190 & 27235 & 4.55 \\
\hline & Trinidad y Tobago & 1359193 & 72623 & 5.34 \\
\hline
\end{tabular}

Fuente: elaboración propia a partir de CIA Factbook (para la población) y "Number of coronavirus (COVID-19) tests performed in selected countries in Latin America and the Caribbean as of January 4, 2021", Statista, https://www.statista.com/statistics/1105907/latin-america-coronaviruscovid-19-tests-country (consulta del 20 de enero de 2021) para las pruebas realizadas. 
